\title{
Impact of Face-to-Face Teaching in Addition to Electronic Learning on Personal Protective Equipment Doffing Proficiency in Student Paramedics: Randomized Controlled Trial
}

\author{
Ludivine Currat ${ }^{1,+}{ }^{+}$, Mélanie Suppan ${ }^{2}$, Birgit Andrea Gartner ${ }^{3}{ }^{(0)}$, Emmanuel Daniel ${ }^{4}$, Mathieu Mayoraz ${ }^{5,6}$, \\ Stephan Harbarth ${ }^{4}$, Laurent Suppan ${ }^{3}(\mathbb{D})$ and Loric Stuby ${ }^{6, *,+}+(\mathbb{C}$
}

check for updates

Citation: Currat, L.; Suppan, M.; Gartner, B.A.; Daniel, E.; Mayoraz, M.; Harbarth, S.; Suppan, L.; Stuby, L. Impact of Face-to-Face Teaching in Addition to Electronic Learning on Personal Protective Equipment Doffing Proficiency in Student Paramedics: Randomized Controlled Trial. Int. J. Environ. Res. Public Health 2022, 19, 3077. https://doi.org/ 10.3390/ijerph19053077

Academic Editors: Zhengchao Dong, Juan Manuel Gorriz and Yudong Zhang

Received: 29 January 2022

Accepted: 3 March 2022

Published: 5 March 2022

Publisher's Note: MDPI stays neutral with regard to jurisdictional claims in published maps and institutional affiliations.

Copyright: (C) 2022 by the authors. Licensee MDPI, Basel, Switzerland. This article is an open access article distributed under the terms and conditions of the Creative Commons Attribution (CC BY) license (https:// creativecommons.org/licenses/by/ $4.0 /)$.
1 A.C.E. Genève Ambulances, Emergency Medical Services, CH-1225 Chêne-Bourg, Switzerland; 1.currat@ace-ambulances.ch

2 Division of Anesthesiology, Department of Anesthesiology, Clinical Pharmacology, Intensive Care and Emergency Medicine, University of Geneva Hospitals and Faculty of Medicine, CH-1211 Geneva, Switzerland; melanie.suppan@hcuge.ch

3 Division of Emergency Medicine, Department of Anesthesiology, Clinical Pharmacology, Intensive Care and Emergency Medicine, University of Geneva Hospitals and Faculty of Medicine, CH-1211 Geneva, Switzerland; birgit.gartner@hcuge.ch (B.A.G.); laurent.suppan@hcuge.ch (L.S.)

4 Infection Control Program and WHO Collaborating Centre on Patient Safety, University of Geneva Hospitals and Faculty of Medicine, CH-1211 Geneva, Switzerland; emmanuel.daniel@hcuge.ch (E.D.); stephan.harbarth@hcuge.ch (S.H.)

5 MEDI-Center for Medical Education, College of Higher Education in Ambulance Care, CH-3014 Bern, Switzerland; mathieu.mayoraz@medi.ch

6 Genève TEAM Ambulances, Emergency Medical Services, CH-1201 Geneva, Switzerland

* Correspondence: 1.stuby@gt-ambulances.ch

+ These authors contributed equally to this work.

Abstract: Personal protective equipment doffing is a complex procedure that needs to be adequately performed to prevent health care worker contamination. During the COVID-19 pandemic, junior health care workers and students of different health care professions who had not been trained to carry out such procedures were often called upon to take care of infected patients. To limit direct contact, distance teaching interventions were used, but different trials found that their impact was rather limited. We therefore designed and carried out a randomized controlled trial assessing the impact of adding a face-to-face intervention using Peyton's four-step approach to a gamified e-learning module. Sixty-five student paramedics participated in this study. The proportion of doffing sequences correctly performed was higher in the blended learning group (33.3\% (95\%CI 18.0 to 51.8 ) versus $9.7 \%$ (95\%CI 2.0 to 25.8$), p=0.03$ ). Moreover, knowledge and skill retention four to eight weeks after the teaching intervention were also higher in this group. Even though this study supports the use of a blended learning approach to teach doffing sequences, the low number of student paramedics able to adequately perform this procedure supports the need for iterative training sessions. Further studies should determine how often such sessions should be carried out.

Keywords: personal protective equipment; electronic learning; prehospital; student paramedics; infection prevention; face-to-face learning; randomized controlled trial; Peyton's approach; blended learning

\section{Introduction}

\subsection{Background and Importance}

The COVID-19 pandemic has highlighted the key role of personal protective equipment (PPE) and revealed that many HCWs lack both knowledge and training regarding this equipment [1,2]. Efficient and adequate PPE use is, however, of paramount importance to avoid contaminating both patients and HCWs [3,4]. While correctly donning PPE is of critical importance, many studies have shown that contamination usually occurs during 
the doffing phase [5-10]. In addition, donning and doffing PPE in non-dedicated spaces with time constraints increase the contamination risk even further [11,12].

Training HCWs is an efficient way of decreasing self-contamination during PPE doffing [13-17]. A recent systematic review concluded to the superiority of face-to-face training over passive training only (i.e., text documents or video) regarding PPE doffing procedure compliance [18]. However, the evidence retrieved was considered to be of rather low quality; thus, the authors highlighted the need of further clinical trials for comparing training methods.

A gamified e-learning module tailored to the needs of prehospital providers was previously developed [19]. The impact of this intervention was however limited [20,21]. While distance learning was strongly promoted during the first wave of the COVID-19 pandemic [22,23], complex skills undoubtedly require a blended learning approach, combining workshops and other teaching interventions [24-26]. Such workshops could rely on Peyton's four-step educational approach [27], which has been shown to be more efficient at teaching procedural skills to HCWs than a standard teaching approach [28]. Our hypothesis was that using a blended learning strategy by adding a workshop using Peyton's approach to an interactive, gamified e-learning module would increase knowledge and skill acquisition and retention regarding PPE doffing procedures in student paramedics. Adhering to Peyton's approach was thought to be of particular interest since this method is also used during continuous training sessions followed by paramedics in Switzerland [29,30].

\subsection{Objectives}

The goal of this randomized clinical trial (RCT) was to determine whether adding a face-to-face teaching intervention (following Peyton's approach) to a gamified e-learning module could improve correct doffing sequences' skills and knowledge and retention in student paramedics.

\section{Materials and Methods}

\subsection{Study Design and Setting}

This was a parallel-group, randomized, triple-blind (participants, instructors, and outcome assessors) controlled superiority trial prospectively registered (International Registered Report Identifier PRR1-10.2196/26927) (Figure 1). The protocol has been previously published [31]. It is reported according to the Consolidated Standards of Reporting Trials (CONSORT)-EHEALTH checklist [32] and includes relevant elements from the Checklist for Reporting Results of Internet E-Surveys (CHERRIES) since online questionnaires were used in this study [33]. The regional ethics committee delivered a declaration of non-objection as to conducting this RCT (Req-2020-01340).

All first-year students $(n=65)$ from the Colleges of Higher Education in Ambulance Care located in Bern and Geneva, Switzerland, were invited to participate in this study. To allow the first-year German-speaking students to participate in the study, the study material including the e-learning module was translated in German. There were no exclusion criteria. No incentive was provided.

Instructors, recruited for study purposes, were informed that the objective was to teach the non-contaminating doffing of PPE to first-year students during two training sessions. They were not aware of the study design, and were therefore blinded to the existence of two different training paths. The instructors received a detailed PPE doffing procedure and a summary sheet of the Peyton's approach steps as a reminder during the sessions. They were previously trained by investigators about the doffing procedure and Peyton's pedagogical approach. The instructor:learner ratio was planned to range from 1:1 to 1:3 as such ratios have been shown to be particularly effective [28]. 


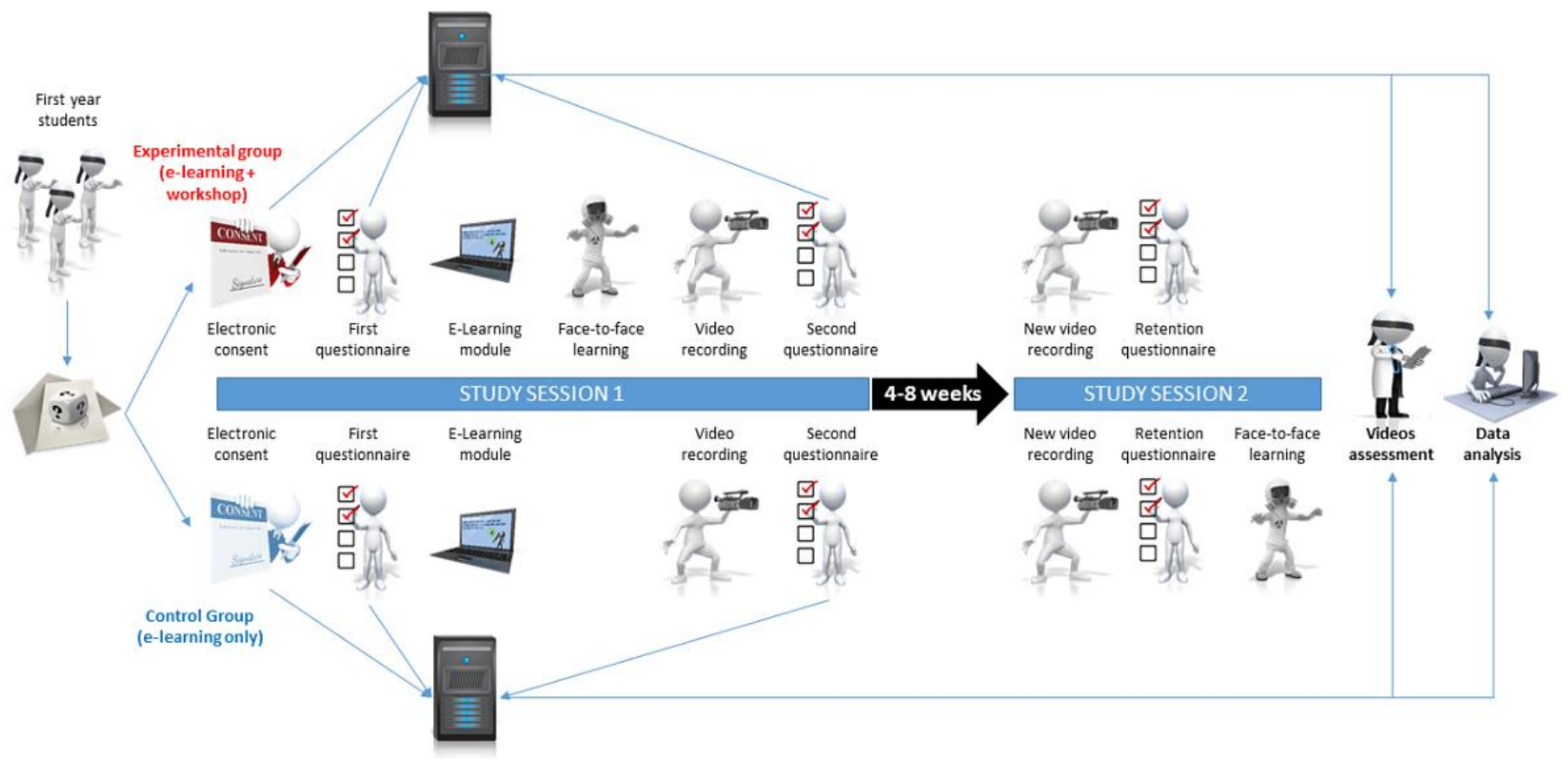

Figure 1. Study design, adapted from Stuby et al., 2021 [31].

\subsection{Online Platform}

An online platform [34] running under the Joomla! 3.9 content management system (Open Source Matters) was developed by LSu for the study's purpose and thoroughly tested by 3 other authors.

\subsection{Randomization and Concealment of Allocation}

An investigator (MS), who did not know the participants and had no contact with them, created unique study accounts, which were then randomized into two groups according to a computer-generated list [35] with a 1:1 allocation ratio and stratification by school and language. Opaque, sealed envelopes containing individual login information were created and transmitted to local investigators. Given the utter lack of risk for the participants, there was no unblinding procedure, no data monitoring, and no interim analysis. Participants were randomly divided between the instructors by an investigator (LSt or LC) using an online team generator [36].

\subsection{Enrolment and Consent}

Prior to the beginning of the study, an email containing information about the study was sent to the participants. Prior to logging in, the learning objectives and a data security statement were displayed on the website home screen. Consent was obtained electronically.

\subsection{Study Sequence}

After clicking the start button, a first questionnaire designed to collect demographic data and assess learning differences according to the VARK (visual, aural, reading/writing, or kinesthetic) modalities was displayed. Both groups were then invited to follow an interactive, gamified e-learning module [19].

After completing the module, participants belonging to the control group were asked to don the following PPE: protective glasses, N95 respirator mask, coverall with hood, and gloves. They were then asked to perform individually the doffing sequence, which was recorded on video. After completing this procedure, participants were asked to return to the online platform to electronically rebuild the doffing sequence. 
Instead of immediately donning and doffing PPE after completing the e-learning module, participants in the experimental group were randomly assigned to one of the instructors to follow face-to-face learning according to Peyton's 4-step approach. After this workshop, these participants resumed the same path as their peers from the control group by moving on to the recording of the doffing sequence on video and were then asked to rebuild the doffing sequence on the online platform.

Four to eight weeks after this initial intervention, depending on the schools' schedules, participants were invited to a second session. Both groups first repeated the video recording of the PPE doffing sequence, then logged into the platform to electronically rebuild the doffing sequence. The experimental group was then considered as having completed the study path, while the control group attended a face-to-face learning session to ensure that all participants had ultimately been given the same level of training regardless of their initial allocation.

\subsection{Gamified E-Learning Module}

The development of the infection prevention and control (IPC) gamified e-learning module used in the present study has already been described [19]. Briefly, this module was developed following the theory-driven approach of the SERES framework [37,38]. It includes several learning objectives and provides general knowledge regarding SARS-CoV-2 (definition, incubation time, transmission routes, and symptoms), PPE items, and donning and doffing sequences. Gamification mechanisms were used to facilitate knowledge acquisition regarding donning and doffing sequences. This gamified module was also used to describe and detail the concept of "contaminated" and "noncontaminated" zones, thus separating the doffing procedure in two specific phases. The specific doffing steps occurring in each zone are detailed in Table S1 in Supplementary File S1.

\subsection{Face-to-Face Learning}

Face-to-face teaching was based on Peyton's approach [27] and followed these steps:

(1) The instructor performed a complete doffing sequence without giving any comments;

(2) The instructor performed a doffing sequence accompanied by step-by-step explanations (description of key points);

(3) Learners were asked to guide the instructor through the doffing sequence, step by step;

(4) Learners were asked to perform the complete doffing sequence before receiving individualized feedback. Each participant performed this step only once.

\subsection{Primary Outcome}

The primary outcome was the proportion of doffing sequences correctly performed after knowledge acquisition during the first study session. The adequacy of the procedure was individually assessed by two investigators (one of whom is an IPC specialist and the other an emergency medicine physician). These investigators, who were blinded as to group allocation, viewed the videos and completed a checklist (Table S2 in Supplementary File S2). In case of disagreement, the study protocol stated that a consensus would be reached by discussion. However, due to logistic reasons, disagreements were solved by asking a third investigator (MS) to individually review the recordings. This investigator was not provided with the ratings given by the other investigators. Her assessments allowed us to address all disagreements as all the ratings were binary (either correct or incorrect).

\subsection{Secondary Outcomes}

Nine secondary outcomes were assessed. Seven of them were prespecified in the study protocol: time required to teach the technique, time required to perform the doffing procedure, learner satisfaction, proportion of correct computer sequences, confidence in using PPE, and knowledge and skill retention. The last two were decided during study sessions and before the constitution of the database: proportion of correct hand disinfection, and number of errors (procedure deviations and/or contaminations) during the procedure. 
Analyzing the proportion of correct hand disinfection was decided as some investigators quickly noticed that, during the study sessions, some of the hand disinfection procedures were incorrect. As this action was not specifically taught in either group, it was decided to consider that the doffing procedure was correct if the hand disinfection procedure was performed at the correct time point, even if it was poorly executed. The entire PPE doffing procedure, which was validated by IPC experts, is detailed in Table S1. However, as hand disinfection is a critical IPC procedure, it was decided to assess it separately. Adequate friction time and proper disinfection of all hand's areas were assessed subjectively.

The number of errors was added as secondary outcome because it allows a more precise assessment of the overall performance than a binary outcome. Furthermore, the risk of contamination is probably not binary and would be expected to increase as the number of errors increases.

\subsection{Blinded Data Collection and Assessment}

Some outcomes were recorded electronically allowing their assessment to be independent from subjective human assessment. For the other outcomes, assessors were blinded to participants' allocation. In case of disagreements, we chose to ask MS to review the recordings in order to reach a consensus.

\subsection{Data Availability}

All investigators were able to access the curated and coded data set. The database is available as Supplementary File S3. The video recordings were used only for the purpose of this study and were destroyed after analysis.

\subsection{Sample Size}

In two previous studies, no participant was able to electronically rebuild the correct doffing sequence after following the gamified e-learning module used in the present study $[20,21]$. However, the practical reality (skill) could be dissociated from the theoretical responses (knowledge) collected on the online platform, which made it necessary to set up a control group in this study.

It was calculated that 46 participants would be needed to have a $90 \%$ chance of detecting, at the 5\% significance level, an increase in the primary outcome from $10 \%$ in the control group to $50 \%$ in the experimental group; additional participants were accepted as the training was part of their curriculum.

\subsection{Statistical Analysis}

Data analysis was performed using Stata 15.1 (StataCorp. 2017. Stata Statistical Software: Release 15. StataCorp LLC, College Station, TX, USA). Due to the small sample size, only non-parametric tests were used. Fisher's exact test was used for dichotomous variables and the Mann-Whitney U test for continuous variables. The computerized doffing sequence accuracy was analyzed as a whole, and according to the respective doffing zones (contaminated and noncontaminated zones). The Likert scales were described graphically, and statistical comparison performed using Fisher's exact test. Conversely to what was stated in the statistical analysis plan of the protocol, they were not dichotomized for statistical analysis (specified before statistical analysis, due to important loss of information). The results were described as a percentage with $95 \% \mathrm{CI}$ for the proportions and according to the median $(\mathrm{Q} 1 ; \mathrm{Q} 3)$ for the continuous variables. A $p$ value $<0.05$ was considered significant. A prespecified subgroup analysis by working status (actively working in an ambulance service or not) was carried out as an increased rate in adequate choice of PPE has been shown in this subgroup [20]. Working status was assessed through the first questionnaire. There were no missing data.

Two post hoc analyses were decided: the estimation of the correlation between the time needed to perform the procedure and the number of errors made, and the search for an association between the VARK scores and the performance and experience (satisfaction 
and confidence) of the participants. For the first, after graphical description, the Pearson correlation coefficient was used. For the second, the association was sought using logistic and linear regression models with the VARK scores as predictive and adjustment variables and the performance (correct/incorrect sequence, and number of errors, respectively).

\subsection{Protocol Deviations}

The protocol deviations were the following: addition of two secondary outcomes (hand disinfection and number of errors in the doffing procedure); way to reach consensus slightly modified; unblinded statistical analysis due to sending of an unblinded data set to statistical analyst (all data had however been entirely acquired); non-dichotomization of Likert scales (decided before statistical analysis due to loss of information); use of a teacher rather than third-year students for the face-to-face teaching due to headmaster's decision leading to the addition of a sensitivity analysis of primary outcome; face-to-face teaching ratio higher than 1:3 once, due to availability of only one German-speaking instructor during the session.

\section{Results}

Sixty-five participants were enrolled in the study. One was excluded after missing the first study session (Figure 2). Their characteristics are detailed in Table 1. All sessions but one $(17 / 18)$ were conducted with an instructor:learner ratio of $1: 1$ to $1: 3$, with one exception of $1: 4$.

Table 1. Participants' characteristics.

\begin{tabular}{lcc}
\hline & E-Learning $(\mathbf{n}=\mathbf{3 1})$ & Blended Learning $\mathbf{( n = 3 3 )}$ \\
\hline Age, in years, median (Q1;Q3) & $24(22 ; 26)$ & $27(23 ; 28)$ \\
Gender, $\mathrm{n}(\%)$ & & \\
Male & $13(41.9)$ & $13(39.4)$ \\
Female & $18(58.1)$ & $20(60.6)$ \\
Other & $0(0.0)$ & $0(0.0)$ \\
\hline Location, $\mathrm{n}(\%)$ & & \\
Geneva & $8(25.8)$ & $10(30.3)$ \\
Bern (French-speaking) & $5(16.1)$ & $5(15.2)$ \\
Bern (German-speaking) & $18(58.1)$ & $18(54.6)$ \\
\hline Actively working in an & & \\
ambulance service, $\mathrm{n}(\%)$ & $24(77.4)$ & $24(72.7)$ \\
\hline Canton of practice of those & & \\
currently working, $(\%)$ & & \\
Aargau & & $1(4.2)$ \\
Basel & $4(16.7)$ & $3(12.5)$ \\
Bern & $0(0.0)$ & $12(50.0)$ \\
Fribourg & $13(54.2)$ & $2(8.3)$ \\
Geneva & $0(0.0)$ & $0(0.0)$ \\
Neuchâtel & $1(4.2)$ & $1(4.2)$ \\
Solothurn & $1(4.2)$ & $2(8.3)$ \\
Vaud & $1(4.2)$ & $2(8.3)$ \\
Valais & $2(8.3)$ & $1(4.2)$ \\
\hline VARK scores, median (Q1;Q3) & $2(8.3)$ & $6(4 ; 7)$ \\
visual & & $5(3 ; 11)$ \\
aural & $7(5 ; 9)$ & $9(8 ; 10)$ \\
read & $8(5 ; 11)$ & \\
kinesthetic & $5(3 ; 6)$ & \\
\hline
\end{tabular}

Total may be over $100 \%$ due to rounding. 


\section{CONSORT 2010 Flow Diagram}

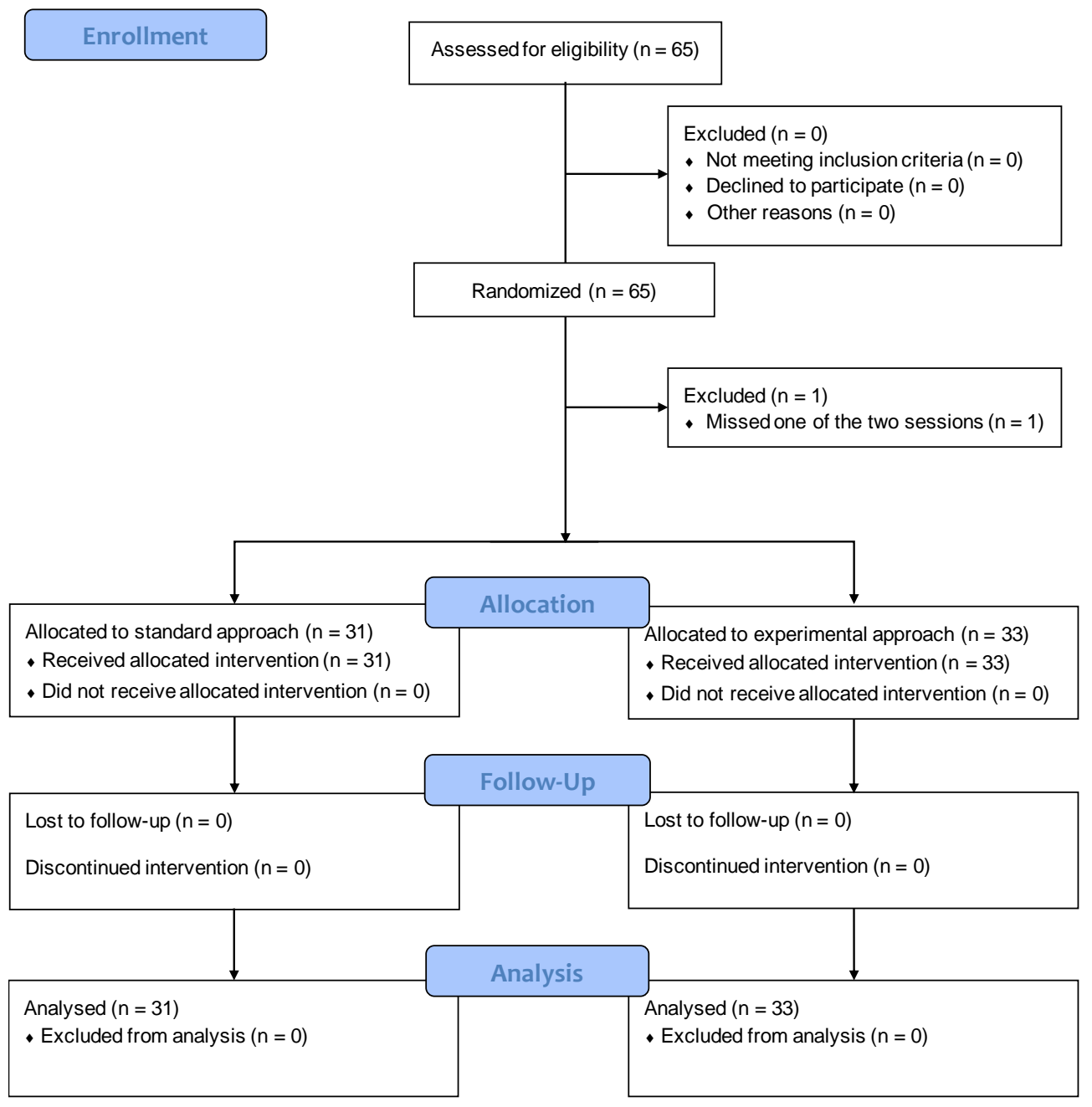

Figure 2. Study flowchart.

The proportion of doffing sequences correctly performed was higher in the group who followed the blended learning compared to the one who followed only the e-learning (33.3\% (95\%CI 18.0 to 51.8 ) versus $9.7 \%$ (95\%CI 2.0 to 25.8$), p=0.03)$. The pre-specified subgroup analysis did not change the direction, nor the magnitude of effect (Table 2).

Table 2. Subgroup analysis of primary outcome by working status.

\begin{tabular}{cccc}
\hline & $\begin{array}{c}\text { E-Learning } \\
(\mathbf{n}=31)\end{array}$ & $\begin{array}{c}\text { Blended Learning } \\
(\mathbf{n}=33)\end{array}$ & $p$-Value \\
\hline $\begin{array}{c}\text { Correct sequence among } \\
\text { participants actively } \\
\text { working, \% }(95 \% \mathrm{CI})\end{array}$ & $8.3 \%(1.0$ to 27.0$)$ & $29.2 \%(12.6$ to 51.1$)$ & 0.14 \\
\hline $\begin{array}{c}\text { Correct sequence among } \\
\text { participants not actively } \\
\text { working, } \%(95 \% \mathrm{CI})\end{array}$ & $14.3 \%(0.3$ to 57.9$)$ & $44.4 \%(13.7$ to 78.8$)$ & 0.31 \\
\hline
\end{tabular}

For the face-to-face teaching, the additional median $(\mathrm{Q} 1 ; \mathrm{Q} 3)$ time required was $22(19 ; 25)$ minutes. There was no significant difference, either in the time required to perform the doffing procedure, nor in the knowledge at acquisition (independently of the 
zones) (Table 3). Knowledge retention and doffing skills in the contaminated zone were significantly higher in the blended learning group (Table 3).

Table 3. Secondary outcomes.

\begin{tabular}{|c|c|c|c|}
\hline & $\begin{array}{l}\text { E-Learning } \\
(\mathrm{n}=31)\end{array}$ & $\begin{array}{l}\text { Blended Learning } \\
\quad(\mathrm{n}=33)\end{array}$ & $p$-Value \\
\hline $\begin{array}{c}\text { Time required to perform the } \\
\text { doffing procedure at first } \\
\text { session, in seconds, median } \\
\text { (Q1;Q3) }\end{array}$ & $133(107 ; 151)$ & $129(118 ; 164)$ & 0.59 \\
\hline $\begin{array}{l}\text { Time required to perform the } \\
\text { doffing procedure remotely, in } \\
\text { seconds, median }(\mathrm{Q} 1 ; \mathrm{Q} 3)\end{array}$ & $113(93 ; 135)$ & $124(113 ; 144)$ & 0.08 \\
\hline $\begin{array}{c}\text { Correct computerized } \\
\text { sequence at first session in } \\
\text { contaminated zone (knowledge } \\
\text { at acquisition), \% (95\%CI) }\end{array}$ & $80.6 \%(62.5$ to 92.5$)$ & $90.9 \%(75.0$ to 98.1$)$ & 0.30 \\
\hline $\begin{array}{c}\text { Correct computerized } \\
\text { sequence at first session in } \\
\text { non-contaminated zone } \\
\text { (knowledge at acquisition), } \\
\%(95 \% \mathrm{CI})\end{array}$ & $77.4 \%$ (58.9 to 90.4$)$ & $72.7 \%$ (54.7 to 86.7$)$ & 0.78 \\
\hline $\begin{array}{c}\text { Correct computerized full } \\
\text { sequence at first session } \\
\text { (knowledge at acquisition), } \\
\%(95 \% \mathrm{CI})\end{array}$ & $64.5 \%(45.4$ to 80.8$)$ & $66.7 \%(48.2$ to 82.0$)$ & 1.00 \\
\hline $\begin{array}{c}\text { Correct computerized } \\
\text { sequence remotely in } \\
\text { contaminated zone at second } \\
\text { session (knowledge retention), } \\
\%(95 \% \mathrm{CI})\end{array}$ & $38.7 \%$ (21.8 to 57.8$)$ & $66.7 \%(48.2$ to 82.0$)$ & 0.04 \\
\hline $\begin{array}{l}\text { Correct computerized } \\
\text { sequence at second session in } \\
\text { non-contaminated zone } \\
\text { (knowledge retention), } \\
\%(95 \% \mathrm{CI})\end{array}$ & $64.5 \%(45.4$ to 80.8$)$ & $75.7 \%$ (57.7 to 88.9$)$ & 0.42 \\
\hline $\begin{array}{c}\text { Correct computerized full } \\
\text { sequence at second session } \\
\text { (knowledge retention), } \\
\%(95 \% \mathrm{CI})\end{array}$ & $35.5 \%(19.2$ to 54.6$)$ & $48.5 \%(30.8$ to 66.4$)$ & 0.32 \\
\hline $\begin{array}{c}\text { Doffing sequences correctly } \\
\text { performed remotely at second } \\
\text { session (skill retention), } \\
\%(95 \% \mathrm{CI})\end{array}$ & $3.2 \%(0.1$ to 16.8$)$ & $24.2 \%(11.1$ to 42.3$)$ & 0.03 \\
\hline
\end{tabular}

The number of errors was significantly lower in the experimental group (Figure 3, Table 4). A weak correlation (first session, $\mathrm{r}=-0.31, p=0.012$, second session, $\mathrm{r}=-0.33$, $p=0.007$ ) was found between the time needed to perform the procedure and the number of errors made (Figure 4 ). There was a 0.74 error per minute decrease (95\%CI 0.17 to 1.32 , $p=0.012)$ during the first sessions and a 1.41 error per minute decrease $(95 \%$ CI 0.40 to 2.42 , $p=0.007)$ during the second sessions. The predictivity of this model is however very low ( $\mathrm{r}$ squared $=0.1$ for both sessions). 


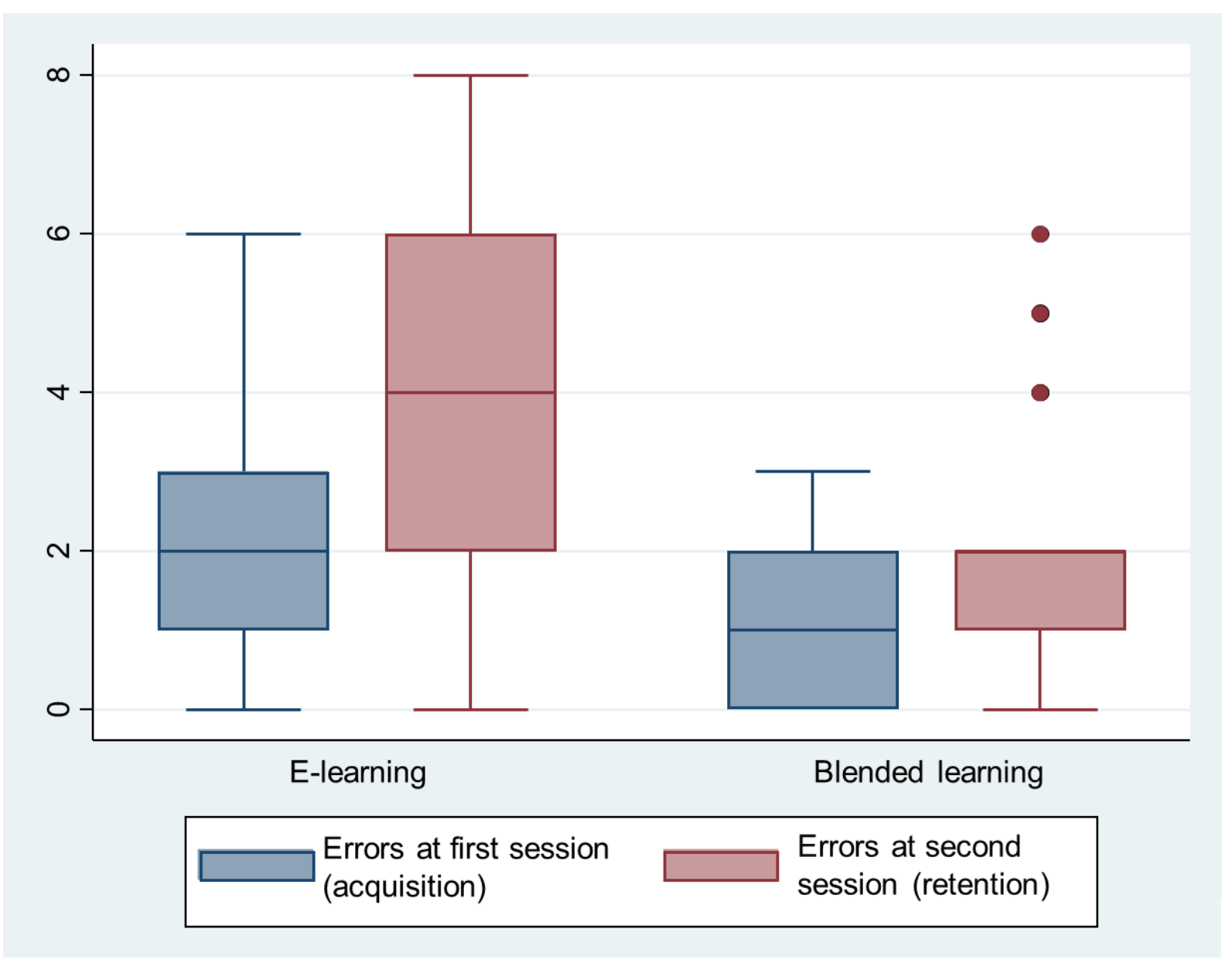

Figure 3. Number of errors by session.
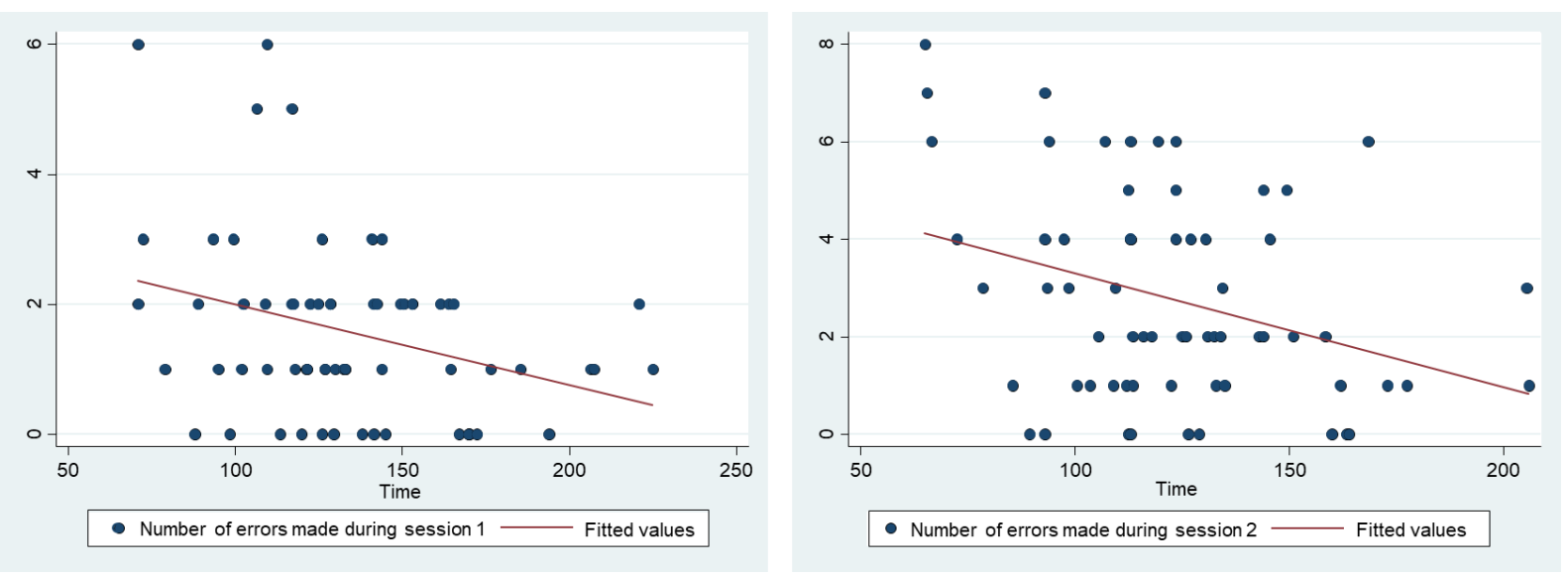

Figure 4. Correlation between time required to perform the doffing procedure and number of errors made.

A common error concerned hand disinfection with $45.3 \%$ of overall participants performing it incorrectly during the first session, and $50.0 \%$ at the second session, with less errors in the experimental group (not statistically different) (Table 4).

Satisfaction (Figure 5) and confidence in using PPE (Figure 6) were significantly different between groups ( $p=0.016$ and $p<0.001$, respectively). 
Table 4. Number of errors by session and hand disinfection.

\begin{tabular}{cccc}
\hline & $\begin{array}{c}\text { E-Learning } \\
(\mathbf{n}=31)\end{array}$ & $\begin{array}{c}\text { Blended Learning } \\
(\mathbf{n}=33)\end{array}$ & $p$-Value \\
\hline $\begin{array}{c}\text { Number of errors in the } \\
\text { procedure at acquisition, } \\
\text { median (Q1;Q3) }\end{array}$ & $2(1 ; 3)$ & $1(0 ; 2)$ & $<0.001$ \\
$\begin{array}{c}\text { Number of errors in the } \\
\text { procedure at retention, } \\
\text { median (Q1;Q3) }\end{array}$ & $4(2 ; 6)$ & $2(1 ; 2)$ & $<0.001$ \\
$\begin{array}{c}\text { Correct hand disinfection at } \\
\text { acquisition, \% (95\%CI) } \\
\begin{array}{c}\text { Correct hand disinfection at } \\
\text { retention, \% (95\%CI) }\end{array}\end{array}$ & $45.2 \%(27.3$ to 64.0$)$ & $63.6 \%(45.1$ to 79.6$)$ & 0.21 \\
\hline
\end{tabular}

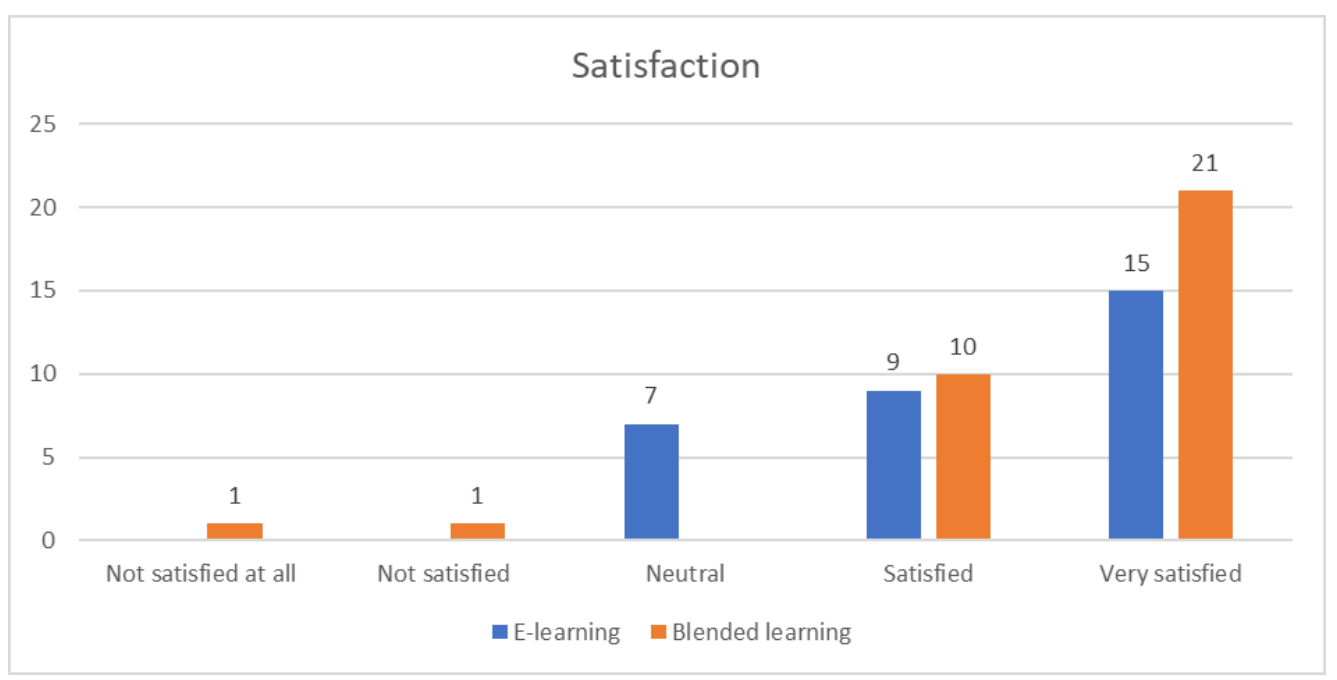

Figure 5. Participant satisfaction.

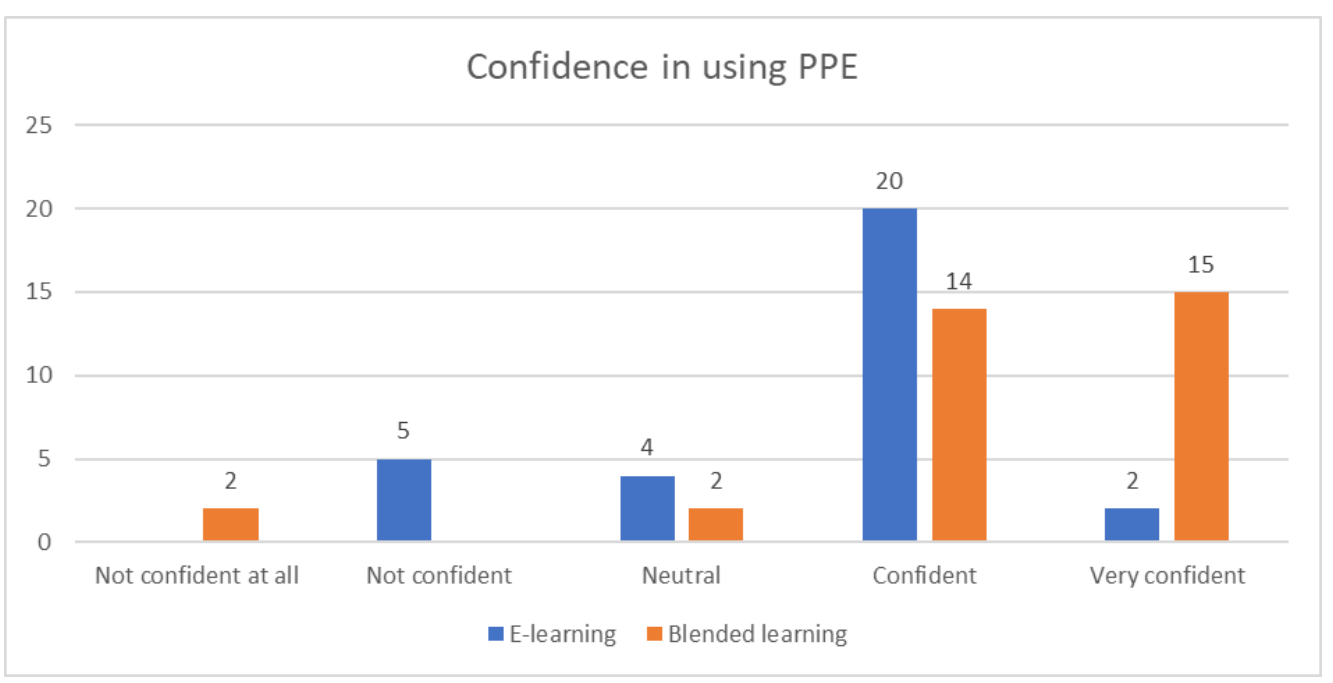

Figure 6. Participant confidence in using personal protective equipment.

By analyzing the primary outcome stratified according to language/type of instructor, there was no change in the direction of the effect, which was, however, only statistically significant in the French-speaking subgroup despite its smaller sample size (Table 5). 
Table 5. Sensitivity analysis of primary outcome (correct doffing procedure) depending on language and type of instructor.

\begin{tabular}{|c|c|c|c|}
\hline & $\begin{array}{l}\text { E-Learning } \\
\quad(n=31)\end{array}$ & $\begin{array}{l}\text { Blended Learning } \\
\quad(n=33)\end{array}$ & $p$-Value \\
\hline $\begin{array}{l}\text { French-speaking participants } \\
\text { with third-year student as } \\
\text { instructor }(n=28), \%(95 \% C I)\end{array}$ & $7.7 \%(0.2$ to 36.0$)$ & $46.7 \%$ (21.3 to 73.4$)$ & 0.04 \\
\hline $\begin{array}{l}\text { German-speaking } \\
\text { participants with teacher as } \\
\text { instructor }(n=36), \%(95 \% C I)\end{array}$ & $11.1 \%(1.4$ to 34.7$)$ & $22.2 \%(6.4$ to 47.6$)$ & 0.66 \\
\hline
\end{tabular}

None of the VARK scores were significantly associated with the performance (regardless of binary or continuous outcome).

\section{Discussion}

\subsection{Main Considerations}

Adding a face-to-face teaching intervention following Peyton's approach to a gamified e-learning module significantly improved PPE doffing skill acquisition in student paramedics. Prior studies have shown that adding training modalities to learning paths increases HCWs compliance and decreases contamination during PPE doffing procedures [17,39-41], can help decrease both the time required to doff PPE and the number of errors [42], and can allow participants to perform complex procedures more efficiently [25,26]. In our study, the superiority of the blended learning approach could be due either to the face-to-face training itself or to the addition of a second training modality. However, there was no difference in the ability of adequately rebuilding the correct PPE doffing sequence on the web platform. This supports the theory that adequately performing a complex procedure such as PPE doffing not only depends on knowledge acquisition but also relies on practical aspects. We therefore believe that using blended learning approaches, including at least a practical skill station, is necessary to teach complex procedures such as PPE doffing. This is further supported by the fact that more students felt "very confident" after following the blended learning approach.

The proportion of student paramedics adequately performing the PPE doffing procedure was lower during the follow-up sessions. However, skill retention was still higher in student paramedics who had followed both interventions in comparison with those who had only followed the e-learning module. Once again, there was no significant difference between groups in the ability of adequately rebuilding the full PPE doffing sequence on the web platform.

During both sessions, the time required to perform the doffing procedure was similar between groups, with shorter times associated with a slightly increased number of errors. Importantly, participants who had only followed the e-learning module made twice as many errors than those who had followed the blended learning approach. Errors during the doffing procedure can lead to self-contamination and increase HCW's risk to contract or transmit diseases [9,43-45]. The more errors HCWs make, the higher the risk [43]. However, not every deviation leads to contamination [43,46], and the risk should therefore be considered according to the kind of error made by the HCW [47]. Since this outcome was not included in the present study, possible contaminations were assessed subjectively without using marking agents (phosphorescence or inactivated virus for instance) [10,43].

Almost one paramedic student out of two did not adequately disinfect hands. Since this procedure is considered as a basic skill, it was neither taught nor reminded in both study arms. Hand disinfection is nevertheless a critically important procedure, and emphasis will need to be put on the importance of adequately performing hand disinfection [48]. Given these unexpectedly low results, particularly in the context of the current pandemic, reminders should therefore be included in all future IPC teaching interventions [49,50] owing to the contamination risk associated with improper hand disinfection $[46,51]$. 
In line with prior studies $[9,52,53]$, the participants who were not actively working in an ambulance service had higher skill acquisition and retention scores. Some authors suggest that complex procedures such as PPE doffing should be taught to HCWs before they acquire inadequate practices [13]. However, this finding could also be due to confounding biases regarding several factors. Indeed, all paramedic students are required to work actively in an Emergency Medical Service (EMS) once they are admitted to one of the two schools involved in this study (Bern's school). Since this school is the only one including German-speaking participants who were taught by a full-fledged teacher rather than by third-year students, the differences seen in our study could be, in part if not entirely, due to these differences.

\subsection{Limitations and Strengths}

This study has several limitations other than the protocol deviations already listed above. First, even though we strived to increase the number of participants by carrying out a multicenter study and translated the previously described e-learning module into German for this purpose, our sample size was still small. This small sample size precluded any strata analysis, and biases linked to the multicenter and multilingual aspects of our study cannot be ruled out. In addition, the planned sample size was not adequate and the post hoc analysis yields a power of $54 \%$. Indeed, we had correctly anticipated that some student paramedics would adequately perform the PPE doffing procedure despite the fact that prior results showed that almost all participants were unable to correctly rebuild the doffing procedure on a web platform. While this supports the theory that practical reality can be dissociated from theoretical responses, we incorrectly estimated the potential increase in PPE doffing skill proficiency after following a blended learning approach. Second, even though our goal was to use only third-year student paramedics as instructors to limit teaching biases during the face-to-face sessions, we had no choice but to use a full-fledged teacher for the subgroup of German-speaking participants. Therefore, the absence of a statistically significant difference between groups in the subset of Germanspeaking participants could be ascribed, at least in part, to this deviation from our original protocol, even though all instructors, regardless of their professional status, received the same training regarding Peyton's approach. Third, we did not foresee that student paramedics might lack skills regarding hand disinfection. Even though this outcome was added after the first recordings had been assessed, there should be little bias as all assessors were blinded as to group allocation.

However, this study also has strengths. First, the robust, stratified randomization method allowed us to obtain well-balanced groups despite the limited sample size. Second, the electronic acquisition of data related to secondary outcomes also helped limit potential assessment biases. Another important strength is the utter lack of dropouts between the initial study session and the follow-up sessions. Finally, this is one of the few studies reporting the impact of adding a face-to-face teaching intervention to a gamified e-learning module.

\subsection{Perspectives and Practical Implications}

First of all, because of the differences found between theoretical responses and actual skills, future studies exploring this domain should include practical skill assessments, even if no skill station is included in the learning path. In addition, studies involving actively working HCWs should consider acquiring video recordings during actual interventions. Indeed, the number of errors in the PPE doffing procedure might actually be higher in the field because of the Hawthorne effect [54-56], narrow spaces, and time constraints.

Chemical, biological, radiological, and nuclear threats are globally increasing but most health care workers (HCWs) are insufficiently trained to face such situations $[57,58]$. Given the unsatisfactory skill acquisition and the even poorer retention of PPE doffing procedural skills in student paramedics even after following a blended learning approach, further studies are needed to understand how the proficiency of prehospital providers can be enhanced regarding this critical procedure. While this could potentially be achieved by 
adding further training modalities, it is also possible that the only way of ensuring adequate skill acquisition and retention is through the provision of regular refresher sessions. The impact of regular refresher sessions has been studied regarding basic life-support skills $[59,60]$, and future studies could be designed to assess the impact of similar sessions regarding PPE doffing skills.

Another important element that future studies should consider is the systematic assessment of computer literacy [61,62]. Indeed, even though we considered that computer literacy should be high in our population of Swiss student paramedics since the vast majority of them are young people living in a high-income country [63], the inconsistency between their actual skills and their ability to adequately rebuild the doffing sequence on a computer platform in prior studies [20] is intriguing. Therefore, we recommend that future research in this domain should always assess computer literacy in any population studied and avoid being prejudiced by potential misconceptions regarding specific populations.

Finally, iterative assessments of PPE doffing skills should be performed and PPE doffing should, whenever possible, be systematically executed under the supervision of proficient and regularly IPC-trained personnel to avoid contamination [64].

\section{Conclusions}

In this study, adding face-to-face training to a gamified e-learning module increased PPE doffing proficiency among first year student paramedics and enhanced skill retention. The proportion of participants able to adequately perform the procedure was, however, rather low, and PPE doffing procedures remain complex to learn, retain, and perform. Future studies are needed to determine whether additional training modalities can enhance skill acquisition and retention, or if regular refresher sessions are the only way of ensuring PPE doffing skills proficiency.

Supplementary Materials: The following supporting information can be downloaded at: https:/ / www.mdpi.com/article/10.3390/ijerph19053077/s1, Table S1: PPE doffing procedure for instructors; Table S2: Assessment grid; CSV file S3: Data set.

Author Contributions: Conceptualization, L.C. and L.S. (Loric Stuby); Data curation, L.C. and L.S. (Laurent Suppan); Formal analysis, L.S. (Loric Stuby); Funding acquisition, L.C.; Investigation, L.C., M.S., B.A.G., E.D., M.M., L.S. (Laurent Suppan) and L.S. (Loric Stuby); Methodology, L.C., M.S., L.S. (Laurent Suppan) and L.S. (Loric Stuby); Project administration, L.C., M.S., L.S. (Laurent Suppan) and L.S. (Loric Stuby); Resources, L.C., M.S., B.A.G., M.M., L.S. (Laurent Suppan) and L.S. (Loric Stuby); Supervision, S.H., L.S. (Laurent Suppan) and L.S. (Loric Stuby); Validation, L.C., M.S., L.S. (Laurent Suppan) and L.S. (Loric Stuby); Visualization, L.S. (Loric Stuby); Writing-original draft, L.C. and L.S. (Loric Stuby); Writing-review \& editing, L.C., M.S., B.A.G., E.D., M.M., S.H., L.S. (Laurent Suppan) and L.S. (Loric Stuby). All authors have read and agreed to the published version of the manuscript.

Funding: The APC was funded by a grant from the Hans Wilsdorf Foundation. Material costs (coveralls, N95 respirator masks) were paid by the Colleges of Higher Education in Ambulance Care.

Institutional Review Board Statement: The study was conducted in accordance with the Declaration of Helsinki. The regional ethics committee delivered a declaration of non-objection as to conducting this RCT (Req-2020-01340).

Informed Consent Statement: Informed consent was obtained from all subjects involved in the study. Written informed consent has been obtained from the participants to publish this paper.

Data Availability Statement: The data presented in this study are available as supplementary material.

Acknowledgments: The authors would like to thank all the participants for their motivation, Karin Bieri, and Marc-Henri Nuoffer for the help with bilingual discussions, Sarah Krieg, Eric Schneider, Coralie Lopez, Cyril Desjacques, Micha Hohl, and Andreas Greub for their engagement to act as instructors, Ksenija Oblak for the videos' German-speaking voice-over, Franco Riva and Yves Meury, schools' headmasters who gave agreement for the conduction of the study, and Heather Lander who gave authorization for use of both French and German VARK questionnaire (c) Copyright Version 8.01 
(2019) held by VARK Learn Limited, Christchurch, New Zealand. A particular thank to Patricia E. Zwahlen for her translation work and craze for the project.

Conflicts of Interest: LSt, LSu, and BG occasionally receive financial compensation when serving as external teaching professional and/or exam expert for the Colleges of Higher Education in Ambulance Care in Geneva and Bern. MM is employed by the Center for Medical Education in Bern as a teacher. The funders had no role in the design of the study; in the collection, analyses, or interpretation of data; in the writing of the manuscript, or in the decision to publish the results.

\section{References}

1. Cash, R.E.; Rivard, M.K.; Camargo, C.A.; Powell, J.R.; Panchal, A.R. Emergency Medical Services Personnel Awareness and Training about Personal Protective Equipment during the COVID-19 Pandemic. Prehospital Emerg. Care 2021, 25, 777-784. [CrossRef] [PubMed]

2. Lamhoot, T.; Ben Shoshan, N.; Eisenberg, H.; Fainberg, G.; Mhiliya, M.; Cohen, N.; Bisker-Kassif, O.; Barak, O.; Weiniger, C.; Capua, T. Emergency Department Impaired Adherence to Personal Protective Equipment Donning and Doffing Protocols during the COVID-19 Pandemic. Isr. J. Health Policy Res. 2021, 10, 41. [CrossRef] [PubMed]

3. Abbas, M.; Robalo Nunes, T.; Martischang, R.; Zingg, W.; Iten, A.; Pittet, D.; Harbarth, S. Nosocomial Transmission and Outbreaks of Coronavirus Disease 2019: The Need to Protect Both Patients and Healthcare Workers. Antimicrob. Resist. Infect. Control 2021, 10, 7. [CrossRef] [PubMed]

4. $\quad$ Barycka, K.; Torlinski, T.; Filipiak, K.J.; Jaguszewski, M.; Nadolny, K.; Szarpak, L. Risk of Self-Contamination among Healthcare Workers in the COVID-19 Pandemic. Am. J. Emerg. Med. 2021, 46, 751-752. [CrossRef]

5. Suen, L.K.P.; Guo, Y.P.; Tong, D.W.K.; Leung, P.H.M.; Lung, D.; Ng, M.S.P.; Lai, T.K.H.; Lo, K.Y.K.; Au-Yeung, C.H.; Yu, W. Self-Contamination during Doffing of Personal Protective Equipment by Healthcare Workers to Prevent Ebola Transmission. Antimicrob. Resist. Infect. Control 2018, 7, 157. [CrossRef]

6. Tomas, M.; Kundrapu, S.; Thota, P.; Sunkesula, V.; Cadnum, J.; Mana, T.; Jencson, A.; O’Donnell, M.; Zabarsky, T.; Hecker, M.; et al. Contamination of Health Care Personnel During Removal of Personal Protective Equipment. JAMA Int. Med. 2015, 175, 1904-1910. [CrossRef]

7. Beam, E.L.; Gibbs, S.G.; Boulter, K.C.; Beckerdite, M.E.; Smith, P.W. A Method for Evaluating Health Care Workers' Personal Protective Equipment Technique. Am. J. Infect. Control 2011, 39, 415-420. [CrossRef]

8. Kang, J.; O’Donnell, J.M.; Colaianne, B.; Bircher, N.; Ren, D.; Smith, K.J. Use of Personal Protective Equipment among Health Care Personnel: Results of Clinical Observations and Simulations. Am. J. Infect. Control 2017, 45, 17-23. [CrossRef]

9. Okamoto, K.; Rhee, Y.; Schoeny, M.; Lolans, K.; Cheng, J.; Reddy, S.; Weinstein, R.A.; Hayden, M.K.; Popovich, K.J.; Centers for Disease Control and Prevention Epicenters Program. Impact of Doffing Errors on Healthcare Worker Self-Contamination When Caring for Patients on Contact Precautions. Infect. Control Hosp. Epidemiol. 2019, 40, 559-565. [CrossRef]

10. Casanova, L.M.; Teal, L.J.; Sickbert-Bennett, E.E.; Anderson, D.J.; Sexton, D.J.; Rutala, W.A.; Weber, D.J. CDC Prevention Epicenters Program Assessment of Self-Contamination during Removal of Personal Protective Equipment for Ebola Patient Care. Infect. Control Hosp. Epidemiol 2016, 37, 1156-1161. [CrossRef]

11. Saran, S.; Gurjar, M.; Garg, A. Identifying and Implementing Strategies to Reduce the Risk of Self-Contamination of Healthcare Workers Caused by Doffing of PPE during COVID-19 Pandemic. Disaster Med. Public Health Prep. 2020, 1-4. [CrossRef] [PubMed]

12. Wundavalli, L.; Singh, S.; Singh, A.R.; Satpathy, S. How to Rapidly Design and Operationalise PPE Donning and Doffing Areas for a COVID-19 Care Facility: Quality Improvement Initiative. BMJ Open Qual. 2020, 9, e001022. [CrossRef] [PubMed]

13. Moore, D.; Gamage, B.; Bryce, E.; Copes, R.; Yassi, A.; BC Interdisciplinary Respiratory Protection Study Group. Protecting Health Care Workers from SARS and Other Respiratory Pathogens: Organizational and Individual Factors That Affect Adherence to Infection Control Guidelines. Am. J. Infect. Control 2005, 33, 88-96. [CrossRef] [PubMed]

14. Savoia, E.; Argentini, G.; Gori, D.; Neri, E.; Piltch-Loeb, R.; Fantini, M.P. Factors Associated with Access and Use of PPE during COVID-19: A Cross-Sectional Study of Italian Physicians. PLoS ONE 2020, 15, e0239024. [CrossRef]

15. Siegel, J.; Rhinehart, E.; Jackson, M.; Chiarello, L. 2007 Guideline for Isolation Precautions: Preventing Transmission of Infectious Agents in Health Care Settings. Am. J. Infect. Control 2007, 35, S65-S164. [CrossRef]

16. Fischer, W.A.; Weber, D.; Wohl, D.A. Personal Protective Equipment: Protecting Health Care Providers in an Ebola Outbreak. Clin. Ther. 2015, 37, 2402-2410. [CrossRef]

17. Hon, C.-Y.; Gamage, B.; Bryce, E.A.; LoChang, J.; Yassi, A.; Maultsaid, D.; Yu, S. Personal Protective Equipment in Health Care: Can Online Infection Control Courses Transfer Knowledge and Improve Proper Selection and Use? Am. J. Infect. Control 2008, 36, e33-e37. [CrossRef]

18. Verbeek, J.H.; Rajamaki, B.; Ijaz, S.; Sauni, R.; Toomey, E.; Blackwood, B.; Tikka, C.; Ruotsalainen, J.H.; Kilinc Balci, F.S. Personal Protective Equipment for Preventing Highly Infectious Diseases Due to Exposure to Contaminated Body Fluids in Healthcare Staff. Cochrane Database Syst. Rev. 2020, 4, CD011621. [CrossRef]

19. Suppan, M.; Gartner, B.; Golay, E.; Stuby, L.; White, M.; Cottet, P.; Abbas, M.; Iten, A.; Harbarth, S.; Suppan, L. Teaching Adequate Prehospital Use of Personal Protective Equipment during the COVID-19 Pandemic: Development of a Gamified e-Learning Module. JMIR Serious Games 2020, 8, e20173. [CrossRef] 
20. Suppan, L.; Stuby, L.; Gartner, B.; Larribau, R.; Iten, A.; Abbas, M.; Harbarth, S.; Suppan, M. Impact of an e-Learning Module on Personal Protective Equipment Knowledge in Student Paramedics: A Randomized Controlled Trial. Antimicrob. Resist. Infect. Control 2020, 9, 1-9. [CrossRef]

21. Suppan, L.; Abbas, M.; Stuby, L.; Cottet, P.; Larribau, R.; Golay, E.; Iten, A.; Harbarth, S.; Gartner, B.; Suppan, M. Effect of an e-Learning Module on Personal Protective Equipment Proficiency among Prehospital Personnel: Web-Based Randomized Controlled Trial. J. Med. Internet Res. 2020, 22, e21265. [CrossRef] [PubMed]

22. Al-Balas, M.; Al-Balas, H.I.; Jaber, H.M.; Obeidat, K.; Al-Balas, H.; Aborajooh, E.A.; Al-Taher, R.; Al-Balas, B. Distance Learning in Clinical Medical Education amid COVID-19 Pandemic in Jordan: Current Situation, Challenges, and Perspectives. BMC Med. Educ. 2020, 20, 341. [CrossRef]

23. Khurshid, Z.; De Brún, A.; Moore, G.; McAuliffe, E. Virtual Adaptation of Traditional Healthcare Quality Improvement Training in Response to COVID-19: A Rapid Narrative Review. Hum. Resour. Health 2020, 18, 81. [CrossRef] [PubMed]

24. Vallée, A.; Blacher, J.; Cariou, A.; Sorbets, E. Blended Learning Compared to Traditional Learning in Medical Education: Systematic Review and Meta-Analysis. J. Med. Internet Res. 2020, 22, e16504. [CrossRef]

25. Liu, Q.; Peng, W.; Zhang, F.; Hu, R.; Li, Y.; Yan, W. The Effectiveness of Blended Learning in Health Professions: Systematic Review and Meta-Analysis. J. Med. Internet Res. 2016, 18, e2. [CrossRef]

26. McCutcheon, K.; O'Halloran, P.; Lohan, M. Online Learning versus Blended Learning of Clinical Supervisee Skills with PreRegistration Nursing Students: A Randomised Controlled Trial. Int. J. Nurs. Stud. 2018, 82, 30-39. [CrossRef]

27. Peyton, J.W.R. Teaching E Learning in Medical Practice; Manticore Europe Ltd.: Herts, UK, 1998; ISBN 978-1-900887-00-7.

28. Giacomino, K.; Caliesch, R.; Sattelmayer, K.M. The Effectiveness of the Peyton's 4-Step Teaching Approach on Skill Acquisition of Procedures in Health Professions Education: A Systematic Review and Meta-Analysis with Integrated Meta-Regression. PeerJ 2020, 8, e10129. [CrossRef]

29. Stuby, L.; Jampen, L.; Sierro, J.; Paus, E.; Spichiger, T.; Suppan, L.; Thurre, D. Effect on Chest Compression Fraction of Continuous Manual Compressions with Asynchronous Ventilations Using an I-Gel ${ }^{\circledR}$ versus 30:2 Approach during Simulated Out-of-Hospital Cardiac Arrest: Protocol for a Manikin Multicenter Randomized Controlled Trial. Healthcare 2021, 9, 354. [CrossRef]

30. Stuby, L.; Jampen, L.; Sierro, J.; Bergeron, M.; Paus, E.; Spichiger, T.; Suppan, L.; Thurre, D. Effect of Early Supraglottic Airway Device Insertion on Chest Compression Fraction during Simulated Out-of-Hospital Cardiac Arrest: Randomised Controlled Trial. J. Clin. Med. 2022, 11, 217. [CrossRef]

31. Stuby, L.; Currat, L.; Gartner, B.; Mayoraz, M.; Harbarth, S.; Suppan, L.; Suppan, M. Impact of Face-to-Face Teaching in Addition to Electronic Learning on Personal Protective Equipment Doffing Proficiency in Student Paramedics: Protocol for a Randomized Controlled Trial. JMIR Res. Protoc 2021, 10, e26927. [CrossRef]

32. Eysenbach, G.; CONSORT-EHEALTH Group. CONSORT-EHEALTH: Improving and Standardizing Evaluation Reports of Web-Based and Mobile Health Interventions. J. Med. Internet Res. 2011, 13, e126. [CrossRef] [PubMed]

33. Eysenbach, G. Improving the Quality of Web Surveys: The Checklist for Reporting Results of Internet E-Surveys (CHERRIES). J. Med. Internet Res. 2004, 6, e34. [CrossRef] [PubMed]

34. Online Study Platform. Available online: https:/ / covid-ppe.anesth.ch/ (accessed on 24 November 2020).

35. Create a Blocked Randomisation List I Sealed Envelope. Available online: https:/ /www.sealedenvelope.com/simple-randomiser/ v1/lists (accessed on 6 December 2020).

36. Keamk-Create Random and Balanced Teams. Available online: https://www.keamk.com/ (accessed on 5 January 2021).

37. Verschueren, S.; van Aalst, J.; Bangels, A.-M.; Toelen, J.; Allegaert, K.; Buffel, C.; Vander Stichele, G. Development of CliniPup, a Serious Game Aimed at Reducing Perioperative Anxiety and Pain in Children: Mixed Methods Study. JMIR Serious Games 2019, 7, e12429. [CrossRef] [PubMed]

38. Verschueren, S.; Buffel, C.; Stichele, G.V. Developing Theory-Driven, Evidence-Based Serious Games for Health: Framework Based on Research Community Insights. JMIR Serious Games 2019, 7, e11565. [CrossRef] [PubMed]

39. Salway, R.J.; Williams, T.; Londono, C.; Roblin, P.; Koenig, K.; Arquilla, B. Comparing Training Techniques in Personal Protective Equipment Use. Prehosp. Disaster Med. 2020, 35, 364-371. [CrossRef] [PubMed]

40. Hung, P.-P.; Choi, K.-S.; Chiang, V.C.-L. Using Interactive Computer Simulation for Teaching the Proper Use of Personal Protective Equipment. Comput. Inform. Nurs. 2015, 33, 49-57. [CrossRef]

41. Bleasdale, S.C.; Sikka, M.K.; Moritz, D.C.; Fritzen-Pedicini, C.; Stiehl, E.; Brosseau, L.M.; Jones, R.M. Experience of Chicagoland Acute Care Hospitals in Preparing for Ebola Virus Disease, 2014-2015. J. Occup. Environ. Hyg. 2019, 16, 582-591. [CrossRef]

42. Li, Y.; Wang, Y.; Li, Y.; Zhong, M.; Liu, H.; Wu, C.; Gao, X.; Xia, Z.; Ma, W. Comparison of Repeated Video Display vs Combined Video Display and Live Demonstration as Training Methods to Healthcare Providers for Donning and Doffing Personal Protective Equipment: A Randomized Controlled Trial. Risk Manag. Healthc. Policy 2020, 13, 2325-2335. [CrossRef]

43. Kwon, J.H.; Burnham, C.-A.D.; Reske, K.A.; Liang, S.Y.; Hink, T.; Wallace, M.A.; Shupe, A.; Seiler, S.; Cass, C.; Fraser, V.J.; et al. Assessment of Healthcare Worker Protocol Deviations and Self-Contamination During Personal Protective Equipment Donning and Doffing. Infect. Control Hosp. Epidemiol. 2017, 38, 1077-1083. [CrossRef]

44. Casanova, L.; Alfano-Sobsey, E.; Rutala, W.A.; Weber, D.J.; Sobsey, M. Virus Transfer from Personal Protective Equipment to Healthcare Employees' Skin and Clothing. Emerg. Infect. Dis. 2008, 14, 1291-1293. [CrossRef]

45. Mitchell, A.; Spencer, M.; Edmiston, C. Role of Healthcare Apparel and Other Healthcare Textiles in the Transmission of Pathogens: A Review of the Literature. J. Hosp. Infect. 2015, 90, 285-292. [CrossRef] [PubMed] 
46. Zhang, H.-L.; Yang, S.; Luo, H.-X.; You, J.-P. The Error-Prone Operational Steps and Key Sites of Self-Contamination during Donning and Doffing of Personal Protective Equipment by Health Care Workers. Disaster Med. Public Health Prep. 2021, 1-6. [CrossRef]

47. Mumma, J.M.; Durso, F.T.; Ferguson, A.N.; Gipson, C.L.; Casanova, L.; Erukunuakpor, K.; Kraft, C.S.; Walsh, V.L.; Zimring, C.; DuBose, J.; et al. Human Factors Risk Analyses of a Doffing Protocol for Ebola-Level Personal Protective Equipment: Mapping Errors to Contamination. Clin. Infect. Dis. 2018, 66, 950-958. [CrossRef] [PubMed]

48. Pittet, D.; Hugonnet, S.; Harbarth, S.; Mourouga, P.; Sauvan, V.; Touveneau, S.; Perneger, T.V. Effectiveness of a Hospital-Wide Programme to Improve Compliance with Hand Hygiene. Infection Control Programme. Lancet 2000, 356, 1307-1312. [CrossRef]

49. Boyce, J.M.; Pittet, D. Guideline for Hand Hygiene in Health-Care Settings: Recommendations of the Healthcare Infection Control Practices Advisory Committee and the HICPAC/SHEA/APIC/IDSA Hand Hygiene Task Force. Infect. Control. Hosp. Epidemiol. 2002, 23, S3-S40. [CrossRef]

50. Doronina, O.; Jones, D.; Martello, M.; Biron, A.; Lavoie-Tremblay, M. A Systematic Review on the Effectiveness of Interventions to Improve Hand Hygiene Compliance of Nurses in the Hospital Setting. J. Nurs. Sch. 2017, 49, 143-152. [CrossRef]

51. Rayson, D.; Basinda, N.; Pius, R.A.; Seni, J. Comparison of Hand Hygiene Compliance Self-Assessment and Microbiological Hand Contamination among Healthcare Workers in Mwanza Region, Tanzania. Infect. Prev. Pract. 2021, 3, 100181. [CrossRef] [PubMed]

52. Mitchell, R.; Roth, V.; Gravel, D.; Astrakianakis, G.; Bryce, E.; Forgie, S.; Johnston, L.; Taylor, G.; Vearncombe, M. Canadian Nosocomial Infection Surveillance Program Are Health Care Workers Protected? An Observational Study of Selection and Removal of Personal Protective Equipment in Canadian Acute Care Hospitals. Am. J. Infect. Control 2013, 41, 240-244. [CrossRef]

53. Kim, L.E.; Jeffe, D.B.; Evanoff, B.A.; Mutha, S.; Freeman, B.; Fraser, J. Improved Compliance with Universal Precautions in the Operating Room Following an Educational Intervention. Infect. Control Hosp. Epidemiol. 2001, 22, 522-524. [CrossRef]

54. Sedgwick, P.; Greenwood, N. Understanding the Hawthorne Effect. BMJ 2015, 351, h4672. [CrossRef]

55. Campbell, J.P.; Maxey, V.A.; Watson, W.A. Hawthorne Effect: Implications for Prehospital Research. Ann. Emerg. Med. 1995, 26, 590-594. [CrossRef]

56. Hagel, S.; Reischke, J.; Kesselmeier, M.; Winning, J.; Gastmeier, P.; Brunkhorst, F.M.; Scherag, A.; Pletz, M.W. Quantifying the Hawthorne Effect in Hand Hygiene Compliance Through Comparing Direct Observation with Automated Hand Hygiene Monitoring. Infect. Control Hosp. Epidemiol. 2015, 36, 957-962. [CrossRef] [PubMed]

57. Mortelmans, L.J.M.; Gaakeer, M.I.; Dieltiens, G.; Anseeuw, K.; Sabbe, M.B. Are Dutch Hospitals Prepared for Chemical, Biological, or Radionuclear Incidents? A Survey Study. Prehosp. Disaster Med. 2017, 32, 483-491. [CrossRef] [PubMed]

58. Felemban, E.M.; Youssef, H.A.M.; Al Thobaity, A. Factors Affecting the Decontamination Process in Hospitals in Saudi Arabia. Risk Manag. Healthc. Policy 2021, 14, 357-363. [CrossRef]

59. Abelairas-Gómez, C.; Martinez-Isasi, S.; Barcala-Furelos, R.; Varela-Casal, C.; Carballo-Fazanes, A.; Pichel-López, M.; Fernández Méndez, F.; Otero-Agra, M.; Sanchez Santos, L.; Rodriguez-Nuñez, A. Training Frequency for Educating Schoolchildren in Basic Life Support: Very Brief 4-Month Rolling-Refreshers versus Annual Retraining-a 2-Year Prospective Longitudinal Trial. BMJ Open 2021, 11, e052478. [CrossRef]

60. Saad, R.; Sampaio Favarato, M.H.; Ferreira de Paiva, E.; do Patrocinio Tenorio Nunes, M. Medical Student Skill Retention after Cardiopulmonary Resuscitation Training: A Cross-Sectional Simulation Study. Simul. Healthc. 2019, 14, 351-358. [CrossRef]

61. Lee, J.; Lee, E.-H.; Chae, D. EHealth Literacy Instruments: Systematic Review of Measurement Properties. J. Med. Internet Res. 2021, 23, e30644. [CrossRef]

62. Karnoe, A.; Furstrand, D.; Christensen, K.B.; Norgaard, O.; Kayser, L. Assessing Competencies Needed to Engage with Digital Health Services: Development of the eHealth Literacy Assessment Toolkit. J. Med. Internet Res. 2018, 20, e178. [CrossRef]

63. Matthews, B. Digital Literacy in UK Health Education: What Can Be Learnt from International Research? Contemp. Educ. Technol. 2021, 13, ep317. [CrossRef]

64. Cheng, L.; Chen, L.; Xiao, L.; Zhang, J.; Cheng, Y.; Zhou, L.; Peng, Y.; Liu, L. Problems and Solutions of Personal Protective Equipment Doffing in COVID-19. Open Med. 2020, 15, 605-612. [CrossRef] 